\title{
Uric acid bladder stone associated with a foreign body
}

\author{
D.J. Williams
}

University Department of Pathology, Western Infirmary, Glasgow G11 6NT, UK.

\begin{abstract}
Summary: A uric acid bladder stone is described. This stone was unusual in that it had formed on a foreign body, namely surgical suture material. This phenomenon does not appear to have been described previously.
\end{abstract}

\section{Introduction}

The formation of bladder-stones around foreign bodies is well-known to urologists. This case report describes the occurrence of a pure uric acid stone, which had formed around a length of surgical suture material within the bladder.

\section{Case report}

A 79 year old male had been an insulin dependent diabetic for 3 years. Eleven years before his death, he had had a transvesical prostatectomy and had not complained of any subsequent urological symptoms. Medication, in the 3 years before death, had included a thiazide diuretic for his mild hypertension and salicylates for his transient cerebral ischaemia. Serum uric acid concentration had never been measured.

Post-mortem examination established the cause of death as myocardial infarction. An incidental finding was a firm, orange-yellow semi-circular calculus lying free at the base of a trabeculated and dilated bladder. The stone was $90 \mathrm{~mm}$ long $\times 10 \mathrm{~mm}$ average diameter and contained a nucleus of silk suture material $120 \mathrm{~mm}$ long (Figure 1). A total of $30 \mathrm{~mm}$ of suture material protruded from the ends of the stone. Biochemical analysis of the stone using a wet chemical qualitative technique (Merckognost urinary calculi analysis kit) showed a uric acid composition. Tests for calcium, magnesium, ammonium, cystine, phosphate, carbonate and oxalate were negative.

\section{Comment}

It is perhaps surprising that this man had no urological complaints, given the large size of his bladder calculus.

Correspondence: D.J. Williams, B.Sc., M.B., Ch.B., M.Sc., Ph.D.

Accepted: 6 December 1985

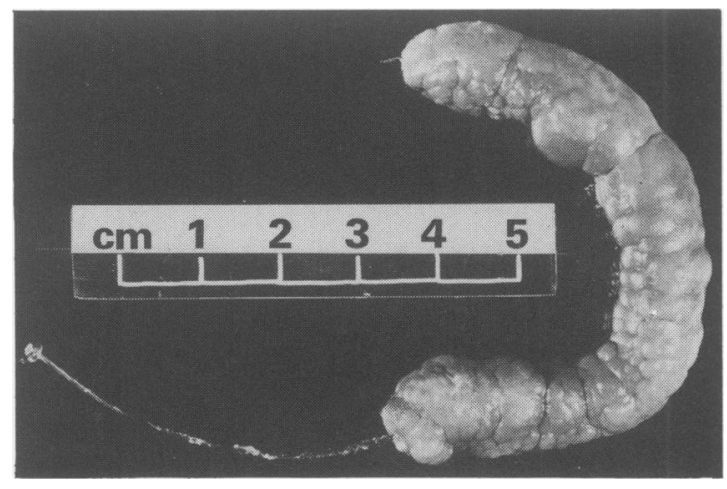

Figure 1 Bladder calculus. Note the suture material at each end of the calculus.

The suture material which provided the nidus for the calculus had presumably found its way into the bladder during prostatectomy. Stones forming around foreign bodies in the bladder usually contain calcium (Smith, 1984). In a case report describing stone formation around suture material, analysis of the stone showed calcium, ammonium, phosphate, oxalate and uric acid (Marks, 1974).

This case is unusual in having only uric acid deposited on a foreign body and such a phenomenon does not, from an extensive literature search, appear to have been reported previously.

\section{Acknowledgements}

Mr Peter Kerrigan is thanked for the photography. Dr I.A.R. More and Mr K.F. Kyle are thanked for helpful advice.

\section{Reference}

MARKS, L.S. (1984). Vesicoureteral reflex from foreign body calculus in the bladder. Journal of Urology, 112, 516.

SMITH, D.R. (1984). In General Urology, 11 th Edition. Lange Medical Publications: Los Altos, California.

C The Fellowship of Postgraduate Medicine, 1986 